\title{
Effect of the time interval between fusion and activation on nuclear state and development in vitro and in vivo of bovine somatic cell nuclear transfer embryos
}

\author{
K I Aston, G P Li, B A Hicks ${ }^{1}$, B R Sessions, B J Pate, D Hammon, T D Bunch and K L White \\ Department of Animal, Dairy, and Veterinary Sciences and Center for Integrated Biosystems, Utah State University, \\ 4815 Old Main Hill, Logan, UT 84322-4815, USA and 'J R Simplot Company Cattle Reproduction Facility, 999 \\ Main Street, Suite 1400, Boise, ID 83702, USA
}

Correspondence should be addressed to Kenneth L White; Email: kwhite@cc.usu.edu

\begin{abstract}
This study indicated that prolonged exposure of donor cell nuclei to oocyte cytoplasm before activation results in abnormal chromatin morphology, and reduced development to compacted morula/blastocyst stage in vitro. However, after transfer of embryos to recipients, there was no difference in pregnancy rates throughout gestation. Chromatin morphology was evaluated for embryos held 2, 3, 4 and $5 \mathrm{~h}$ between fusion and activation. In embryos held $2 \mathrm{~h}, 15 / 17(88.2 \%)$ embryos contained condensed chromosomes, while only $12 / 24(50.0 \%)$ embryos held $3 \mathrm{~h}$ exhibited this characteristic. The proportion of embryos with elongated or fragmented chromosomes tended to increase with increased hold time. While 15/19 (78.9\%) of embryos held $2 \mathrm{~h}$ developed a single pronucleus $6 \mathrm{~h}$ after activation, only 8/22 (36.4\%) had one pronucleus after a 4-h hold. Embryos held 1.0, 1.5, 2.0, 2.5, 3.0, 3.5 and 4.0 h cleaved at rates of 207/281 (73.7\%), 142/166 (85.5\%), 655/912 $(71.8 \%), 212 / 368(57.6 \%), 406 / 667(60.9 \%), 362 / 644(56.2 \%)$ and 120/228 $(52.6 \%)$ respectively. Further development to compacted morula/blastocyst stage occurred at rates of 78/281 (27.8\%), 42/166 (25.3\%), 264/912 (28.9\%), $79 / 368$ $(21.5 \%), 99 / 667(14.8 \%), 94 / 644(14.6 \%)$ and $27 / 228(11.8 \%)$ respectively. Embryos held less than $2.5 \mathrm{~h}$ between fusion and activation established pregnancies in 18/66 (27.3\%) of recipients, while embryos held over $2.5 \mathrm{~h}$ established pregnancies at a rate of $17 / 57(29.8 \%)$. This study indicates that holding bovine nuclear transfer embryos less than $2.5 \mathrm{~h}$ between fusion and activation results in improved nuclear morphology and increased development to compacted morula/blastocyst stage, and results in pregnancy rates equivalent to embryos held over $2.5 \mathrm{~h}$.

Reproduction (2006) $13145-51$
\end{abstract}

\section{Introduction}

Successful somatic cell nuclear transfer (NT) has been achieved in domestic animals and rodents, as reported by the birth of offspring. The overall efficiency of this technique, however, remains low, generally less than $2 \%$ (Hill 2002). A high frequency of early postimplantation developmental arrest and abortion occurs, especially in cattle. The exact mechanism(s) contributing to losses are still unclear. Epigenetic alterations (Wrenzycki et al. 2001, Cezar et al. 2003) and chromosomal abnormalities (Burgoyne et al. 1991, Li et al. 2004a, 2004b) probably contribute to developmental failure.

After the transfer of a differentiated nucleus into an enucleated MII oocyte, the nucleus is disassembled, an event involved in reprogramming the differentiated donor nucleus to a totipotent embryonic state. This disassembly involves nuclear envelope breakdown (NEBD) and premature chromosome condensation (PCC), mediated by high levels of mitosis/meiosis/maturation-promoting factor (MPF) in the oocyte cytoplasm (Czolowska et al. 1984, Barnes et al. 1993, Campbell et al. 1996). These events are followed by erasure of epigenetic modification of DNA, including changes in histone acetylation (Nakao 2001) and DNA methylation (Kang et al. 2003, Shi et al. 2003). Since maternal transcripts are responsible for the events of early embryonic development (Telford et al. 1990), nuclear reprogramming is presumably mediated by factors in the oocyte cytoplasm.

Several groups have shown that the duration of exposure of the donor nucleus to oocyte cytoplasm after NT affects in vitro development; however, the conclusions are mixed. Some reports have indicated that prolonged exposure to the oocyte cytoplasm before activation may be beneficial in promoting embryo development for bovine (Wells et al. 1998, 1999) and murine NT 
(Wakayama et al. 1998). Another study reported that exposure of transferred nuclei to cytoplasm for less than 30 min before activation yielded significantly lower blastocyst development than a $2 \mathrm{~h}$ exposure (Liu et al. 2001). Conversely, other research indicates that excessive exposure of the donor DNA to oocyte cytoplasm results in lower rates of in vitro development in cloned embryos (Akagi et al. 2001). Most recently, Choi et al. (2004) demonstrated that in vitro development of bovine NT embryos to blastocyst decreased as time in hold increased from 1 to $5 \mathrm{~h}$.

Given the conflicting data on the subject, we have evaluated the effect of timing between fusion and activation on NT development. The present study was designed to examine the effect of different time intervals between fusion and activation on structure of the transferred nucleus and embryonic development in vitro and in vivo.

\section{Materials and Methods}

Unless otherwise noted, all reagents used were obtained from MP Biochemicals, Irvine, CA, USA.

\section{Donor cell culture}

Primary bovine fibroblast cultures were established from either lung tissue or ear biopsy. Previous data have demonstrated no difference in in vitro development between lung- and ear-derived donor cells (Kato et al. 2000). Tissues were washed thoroughly and minced, suspended in DMEM/Ham's F12 (1:1) (Hyclone Laboratories, Logan, UT, USA) supplemented with 15\% fetal bovine serum (FBS) (HyClone Laboratories) and $100 \mathrm{U} / \mathrm{ml}$ penicillin $/ 100 \mu \mathrm{g} / \mathrm{ml}$ streptomycin (HyClone Laboratories), seeded in $25 \mathrm{~cm}^{2}$ tissue culture flasks, and cultured at $39{ }^{\circ} \mathrm{C}$ in a humidified atmosphere of $5 \% \mathrm{CO}_{2}$ in air for several days. Cells were then harvested in tissue culture medium containing $10 \%$ DMSO and stored in liquid $\mathrm{N}_{2}$ until use in NT. Frozen/thawed cells were grown to $80-$ $100 \%$ confluence, and passages $2-16$ were used as nuclear donors.

\section{Oocyte maturation}

Maturation of bovine oocytes was performed as described previously (Li et al. 2004a, 2004b). Briefly, cumulus oocyte complexes (COC) were aspirated from $3-8 \mathrm{~mm}$ follicles with an 18 gauge needle from ovaries collected from a local abattoir. Only those with uniform cytoplasm and intact layers of cumulus cells were selected and matured in TCM 199 containing 10\% FBS, $0.5 \mu \mathrm{g} / \mathrm{ml}$ follicle-stimulating hormone (FSH) (Sioux Biochemicals, Sioux City, IA, USA), $5 \mu \mathrm{g} / \mathrm{ml}$ luteinizing hormone (LH) (Sioux Biochemicals), and $100 \mathrm{U} / \mathrm{ml}$ penicillin $/ 100 \mu \mathrm{g} / \mathrm{ml}$ streptomycin for $18-22 \mathrm{~h}$.

\section{Nuclear transfer (NT)}

After maturation, cumulus cells were removed by vortexing COC in PB1 (calcium and magnesium containing PBS (HyClone Laboratories), $0.32 \mathrm{mM}$ sodium pyruvate, $5.55 \mathrm{mM}$ glucose and $3 \mathrm{mg} / \mathrm{ml}$ BSA) medium containing $10 \mathrm{mg} / \mathrm{ml}$ hyaluronidase. Oocytes with a first polar body were used as recipient cytoplasts. Enucleation was employed to remove the first polar body and metaphase plate, and single cells were subsequently transferred to the perivitelline space of recipient cytoplasts. Fusions of NT couplets were performed in mannitol fusion medium (Wells et al. 1999) by two electric DC pulses of $2.2 \mathrm{kV} / \mathrm{cm}$ for $25 \mu \mathrm{s}$. After fusion, embryos were held in CR2 medium supplemented with $3 \%$ FBS for 1.0, 1.5, 2.0, 2.5, 3.0, 3.5 and $4.0 \mathrm{~h}$ before activation. Fused embryos were activated at $23-25 \mathrm{~h}$ after the onset of maturation by exposure to $5 \mu \mathrm{M}$ ionomycin for $5 \mathrm{~min}$ followed by $5 \mathrm{~h}$ incubation in $10 \mu \mathrm{g} / \mathrm{ml}$ cycloheximide.

\section{Nuclear and microtubule assessment by immunofluorescent staining}

Reconstructed embryos were fixed 2, 3, 4 and $5 \mathrm{~h}$ after fusion. Some embryos activated $2-4 \mathrm{~h}$ after fusion were fixed $6 \mathrm{~h}$ after initial activation to evaluate pronuclear morphology. Immunofluorescent staining was performed as reported (Zhu et al. 2003) with some modifications. Briefly, embryos were fixed with $3.7 \%(\mathrm{w} / \mathrm{v})$ paraformaldehyde in PBS overnight at $4{ }^{\circ} \mathrm{C}$. Fixed embryos were extracted in PBS containing 1\% (w/v) Triton X-100 and $0.3 \%$ BSA for $1 \mathrm{~h}$ at $37^{\circ} \mathrm{C}$. After two washes with PBS containing $0.01 \%$ Triton X-100, embryos were blocked in PBS containing $150 \mathrm{mM}$ glycine and $1 \%$ Triton $\mathrm{X}-100$ for $1 \mathrm{~h}$ at $37^{\circ} \mathrm{C}$. The embryos were then incubated for $1 \mathrm{~h}$ at $37^{\circ} \mathrm{C}$ in a mouse monoclonal antibody against $\alpha$-tubulin ( $\mathrm{T}$ 5168; Sigma) diluted $1: 100$ in PBS. They were then washed with PBS and incubated in fluorescein isothiocyanate-labeled goat antimouse IgG (Southern Biotechnology Associates, Birmingham, AL, USA; Cat no. 1030-02) diluted $1: 100$ in PBS for $1 \mathrm{~h}$ at $37^{\circ} \mathrm{C}$. Chromatin was stained with $10 \mu \mathrm{g} / \mathrm{ml}$ propidium iodide. Finally, embryos were mounted on slides with a solution of glycerol and PBS (1:1). The samples were examined under a Zeiss epifluorescent microscope (Carl Zeiss Optical, Chester, VA, USA). Images were captured by digital camera with the PIXERA Viewfinder Program (Pixera Corporation, Los Gatos, CA, USA).

\section{Embryo culture}

After activation, embryos were cultured under mineral oil in $50 \mu \mathrm{l}$ droplets of CR2 with $3 \%$ FBS on a monolayer of bovine cumulus cells at $39^{\circ} \mathrm{C}$ in an atmosphere of $5 \%$ $\mathrm{CO}_{2}$ in air for 6-7 days. Medium was changed every $48 \mathrm{~h}$. Cleavage and compacted morula/blastocyst rates 
were recorded $48 \mathrm{~h}$ and $6-7$ days after activation respectively.

\section{Embryo transfer}

On day 6 or 7, compacted morulae and blastocysts were shipped overnight in equilibrated CR2 at $38.5^{\circ} \mathrm{C}$ to the site of transfer. One to two embryos were transferred nonsurgically to cows synchronized \pm 1 day to the stage of embryonic development. Pregnancy was detected by transrectal ultrasound at embryonic days 25-30.

\section{Statistical analyses}

Data were pooled from at least four replicates per group for the in vitro development studies. Chi-square analysis was used to determine differences in cleavage and development to the compacted morula stage between hold times. Differences in remodeling and nuclear morphology between groups were analyzed by Student's $t$-test. Unless otherwise noted, a probability of $P<0.05$ was considered statistically significant.

\section{Results}

\section{Nuclear morphology}

When the preactivation-reconstructed embryos were examined $2 \mathrm{~h}$ after fusion, the majority of the embryos (88\%, 15/17) possessed condensed chromosomes (Fig. 1a) or a chromosome array resembling the maternal metaphase plate (metaphase-like chromosomes, Fig. 1b) that was significantly higher $(P<0.05)$ than for embryos examined $3 \mathrm{~h}$ after fusion $(50 \%, 12 / 24)$. The proportion of the embryos possessing elongated or scattered chromosomes tended to increase with increasing time between fusion and activation (Table 1). Eighty-two percent of the embryos held $4-5 \mathrm{~h}$ between fusion and activation possessed elongated (Fig. 1c and d) or scattered (Fig. 1e) chromosomes.

Of embryos observed $6 \mathrm{~h}$ after activation, $78.9 \%$ of the embryos activated $2 \mathrm{~h}$ after fusion developed a single pronuclear structure (PN) that was significantly higher than those activated $4 \mathrm{~h}$ after fusion (36.4\%) (Table 2). Of the embryos activated $4 \mathrm{~h}$ after fusion, $63.6 \%$ possessed two or more PN (Fig. 1f-i).

\section{Embryo development in vitro and in vivo}

Cleavage of embryos derived from groups activated $1-2 \mathrm{~h}$ after fusion $(71.8-85.5 \%)$ was significantly higher $(P<0.01)$ than that of embryos held $2.5-4.0 \mathrm{~h}$ between fusion and activation (52.6-60.9\%) (Fig. 2 and Table 3). The compacted morula/blastocyst development of embryos activated $1.0-2.5 \mathrm{~h}$ after fusion (21.5-28.9\%) was higher $(P<0.01)$ than that of embryos activated $3-4 \mathrm{~h}$ after fusion (11.8-14.8\%) (Fig. 2 and Table 3). After transfer of the cloned, compacted morulae/blastocysts to recipients, no differences were observed in day-30 pregnancy rates between embryos held under $2.5 \mathrm{~h}$ (18 pregnancies/66 transfers (27.3\%)) and embryos held over $2.5 \mathrm{~h}$ (17 pregnancies/57 transfers (29.8\%)). Pregnancy retention was evaluated around days 60, 90 and 180, and term, and no differences in pregnancy retention were observed at any stage of gestation, three calves being born in the $<2.5 \mathrm{~h}$ group and one calf in the $>2.5 \mathrm{~h}$ group.
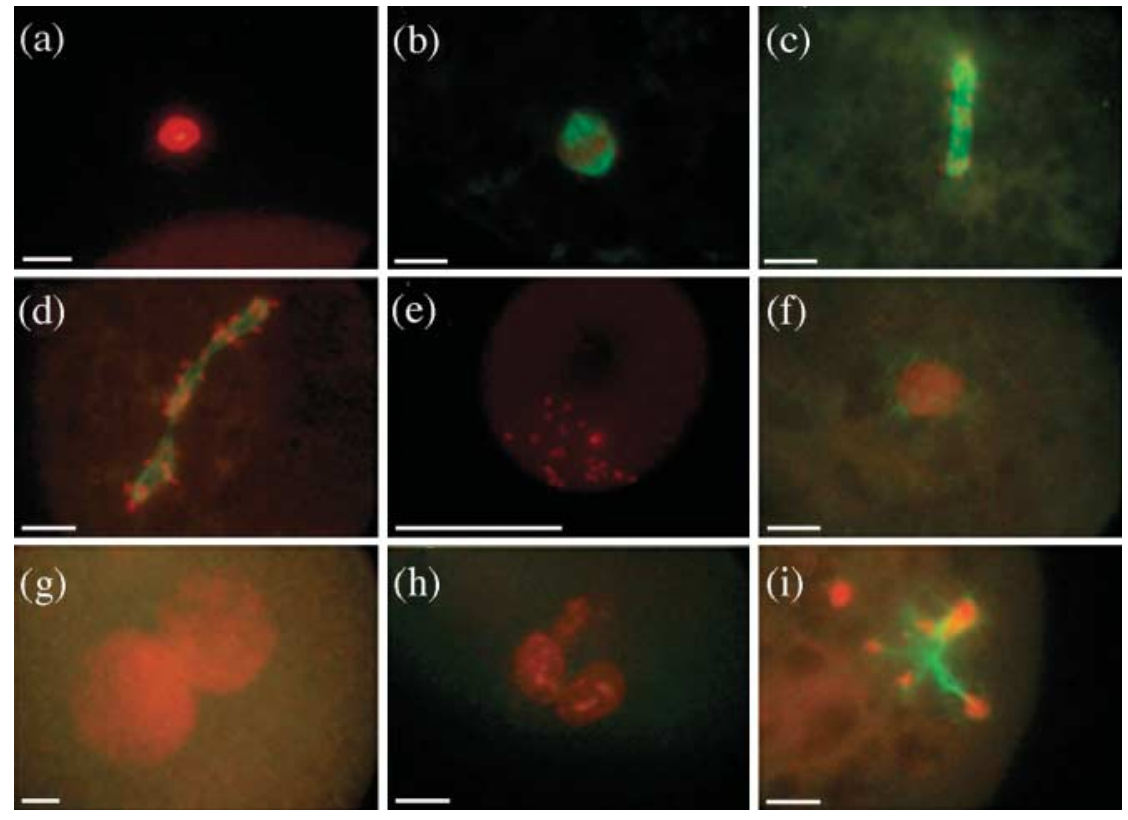

Figure 1 Nuclear remodeling and morphology of bovine nuclear transferred embryos. (a-e) Remodeling of nuclei after fusion. (a) Condensed chromosomes and small microtubule aster among chromatin; (b) metaphase-like chromosomes with strongly stained microtubules; (c and d) elongated chromosomes and microtubules connecting the chromosomes; (e) scattered chromosomes; $(\mathrm{f}-\mathrm{i})$ the representatives of $1 \mathrm{PN}, 2 \mathrm{PN}, 3 \mathrm{PN}$ and $7 \mathrm{PN}$ respectively after activation of fused nuclear transferred embryos. Bars represent $10 \mu \mathrm{M}$. 
Table 1 Remodeling of transferred bovine somatic cells at various times after fusion.

\begin{tabular}{|c|c|c|c|c|c|c|}
\hline \multirow[b]{2}{*}{ Time after fusion $(h)$} & \multirow[b]{2}{*}{ No. embryos examined } & \multicolumn{5}{|c|}{ Nuclear remodelling types (\%) } \\
\hline & & Condensed chr. & Metaphase-like & Elongated chr. & Scattered chr. & $\mathrm{PN}$ \\
\hline 2 & 17 & $9(52.9)^{\mathrm{a}}$ & $6(35.3)^{\mathrm{b}}$ & $2(11.8)^{\mathrm{C}}$ & & \\
\hline 3 & 24 & $2(8.3)^{\mathrm{C}}$ & $10(41.7)^{\mathrm{a}}$ & $9(37.5)^{\mathrm{b}}$ & $3(12.5)^{\mathrm{a}}$ & \\
\hline 4 & 25 & & $2(8)^{\mathrm{C}}$ & $12(48)^{\mathrm{a}}$ & $9(36)^{\mathrm{a}}$ & $2(8)$ \\
\hline 5 & 25 & & $2(8)^{\mathrm{c}}$ & $9(36)^{b}$ & $11(44)^{a}$ & $3(12)$ \\
\hline
\end{tabular}

${ }^{a-c}$ Values with different superscripts in the same column differ from each other at $P<0.05$. Chr.: Chromosomes.

\section{Discussion}

For NT to be successful, the donor nucleus must be properly reprogrammed. During nuclear reprogramming, epigenetic marks are erased from the donor nucleus genome, resulting in an erasure of tissue-specific gene expression patterns, and effectively resetting the cell to a totipotent state (Santos \& Dean 2004). Our studies indicate that the timing between fusion and activation probably has a critical impact on reprogramming.

Studies evaluating DNA methylation patterns in developing NT embryos indicate that demethylation and remethylation events are not always faithfully recapitulated in the mouse (Shi \& Haaf 2002, Chung et al. 2003, Mann et al. 2003) and the cow (Bourc'his et al. 2001, Dean et al. 2001, Kang et al. 2002). It is also clear that histone acetylation is sometimes aberrant in bovine NT embryos (Santos et al. 2003). This incomplete epigenetic reprogramming is the predominant explanation of the frequent aberrant gene expression in NT embryos and the subsequent failures in development (Santos et al. 2003).

The mechanisms responsible for DNA demethylation may follow a pattern of activity similar to MPF with high activity before activation and diminished activity after activation. Further research is required to determine those dynamics, but the study by Dean et al. (2001) suggests a critical window of time in which active demethylation can occur after fusion. The idea of this critical window between fusion and activation is supported by Bourc'his et al. (2001), who did not observe active demethylation when activation was performed at the time of fusion.

Nuclear remodeling is an important element in the process of reprogramming that must occur in NT embryos. Our research, as well as that of others, has demonstrated that chromatin remodeling and blastomere ploidy frequently deviate from normal after NT in various species, including cattle (Booth et al. 2003, Bureau et al. 2003, Li et al. 2004a, 2004b), rabbits (Shi et al. 2004) and pigs (Kim et al. 2005). Several significant morphologic changes occur in the donor nucleus after NT into cytoplasts with high MPF activity. These changes include nuclear envelope breakdown (NEBD) and premature chromosome condensation (PCC) (Czolowska et al. 1984, Campbell et al. 1996). After these two events, the nuclear envelope is reformed, and DNA synthesis commences (Campbell et al. 1993). Aberrations or deficiencies in these events might result in some of the problems associated with early development in NT embryos.

Figure 1C and D show elongated chromosome sets. It is clear how these cells might end up with 2-3 PN (as in Fig. 1G and $\mathrm{H}$ ) after activation, as areas where microtubules are thinner are probably more prone to depolymerization and fragmentation. This is supported by the fact that more elongated chromosome sets were observed with increased time after fusion, and more embryos displayed multiple PN when held $4 \mathrm{~h}$ between fusion and activation than embryos activated $2 \mathrm{~h}$ after fusion. Likewise, a scattered chromosome arrangement, as observed in Fig. 1E, would result in multiple PN after activation. It is also probable that embryos with more than one $\mathrm{PN}$ after activation result in nuclear fragmentation and unbalanced chromosome constitutions.

The amount of time the donor nucleus is exposed to oocyte cytoplasm before activation is critical in subsequent development of NT embryos. Our data suggest that prolonged exposure to arrested MII oocyte cytoplasm results in more frequent structural abnormality in nuclear material, manifesting itself as elongated chromatin before activation and the development of multiple pronuclei after activation.

While it is important to note that the number of morphologically 'normal' embryos before activation (embryos

Table 2 Nuclear morphology of bovine NT embryos $6 \mathrm{~h}$ after activation.

\begin{tabular}{lcccccc}
\hline & & \multicolumn{4}{c}{ Pronucleus (PN) status (\%) } \\
\cline { 3 - 7 } Activation time after fusion $(\mathrm{h})$ & No. embryos examined & $1 \mathrm{PN}$ & $2 \mathrm{PN}$ & $3 \mathrm{PN}$ & $4-8$ PN & Scattered Chr. \\
\hline 2 & 19 & $15(78.9)^{\mathrm{a}}$ & $3(15.8)$ & $1(5.3)$ & 0 & 0 \\
4 & 22 & $8(36.4)^{\mathrm{b}}$ & $4(18.2)$ & $2(9.0)$ & $6(27.3)$ & $2(9.0)$ \\
\hline
\end{tabular}

a,b Values with different superscripts in the same column differ from each other at $P<0.05$. Chr.: Chromosomes. 


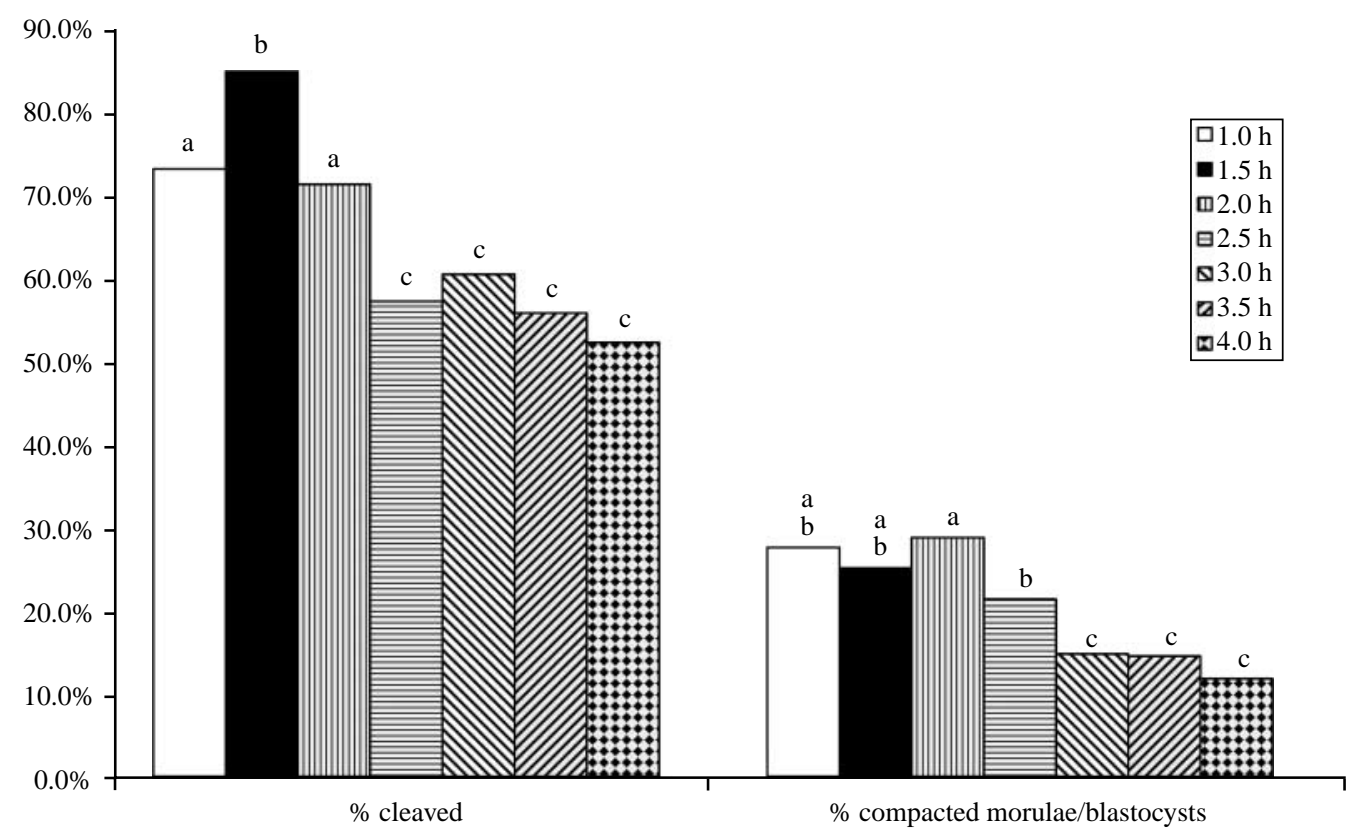

Figure 2 In vitro development of bovine NT embryos based on time between fusion and activation. (a-c) Values with different superscripts in the same group differ from each other at $P<0.01$.

with compacted or metaphase-like chromosomes) and after activation (single PN) declines when embryos are held longer than $3 \mathrm{~h}$ before activation, it is also noteworthy that some embryos held longer do appear normal and develop to compacted morula/blastocyst stage. Our data also indicate that embryos that develop to compacted morula stage have an equal probability of establishing and maintaining pregnancy regardless of hold time, indicating that most embryos negatively affected by prolonged hold time will stop developing before reaching compacted morula stage.

This study evaluated the effect of the duration of exposure of the donor nucleus to MII oocyte cytoplasm before activation on nuclear structure, in vitro development and pregnancy rates after transfer. The data indicate that prolonged exposure to oocyte cytoplasm results in more embryos with elongated or scattered chromosomes before activation, as well as fewer embryos developing a single PN $6 \mathrm{~h}$ after activation. We found that a hold of
$1-2 \mathrm{~h}$ results in higher in vitro development and lower rates of nuclear fragmentation. While in vitro development declines and fragmentation increases with increased hold time, embryos that develop to compacted morula or blastocyst stage are equally likely to establish pregnancy after transfer. According to these data, embryos that are chromosomally compromised probably cease development before reaching compacted morula stage. The data further indicate that $1 \mathrm{~h}$ between fusion and activation provides the donor nucleus with sufficient exposure to MII cytoplasm to initiate critical reprogramming events, and that longer than $2 \mathrm{~h}$ results in reduced viability of embryos in vitro.

The process of nuclear reprogramming during NT is extremely complex and not well understood. There are undoubtedly numerous proteins involved in the process of dedifferentiation that occurs in NT. Even under conditions where proper chromosomal composition is maintained, NT efficiency is still quite low. This indicates that while

Table 3 In vitro development of bovine NT embryos with different hold times.

\begin{tabular}{lccc}
\hline Time in hold $(\mathrm{h})$ & No. cultured & No. cleaved $(\%)$ & No. compacted morulae/blastocysts $(\%)$ \\
\hline 1.0 & 281 & $207(73.7)^{\mathrm{b}}$ & $78(27.7)^{\mathrm{ab}}$ \\
1.5 & 166 & $142(85.5)^{\mathrm{a}}$ & $42(25.3)^{\mathrm{ab}}$ \\
2.0 & 912 & $655(71.8)^{\mathrm{b}}$ & $264(28.9)^{\mathrm{a}}$ \\
2.5 & 368 & $212(57.6)^{\mathrm{a}}$ & $79(21.5)^{\mathrm{b}}$ \\
3.0 & 667 & $406(60.9)^{\mathrm{c}}$ & $99(14.8)^{\mathrm{c}}$ \\
3.5 & 644 & $362(56.2)^{\mathrm{c}}$ & $94(14.6)^{\mathrm{c}}$ \\
4.0 & 228 & $120(52.6)^{\mathrm{c}}$ & $27(11.8)^{\mathrm{c}}$ \\
\hline
\end{tabular}

\footnotetext{
${ }^{a-c}$ Values with different superscripts in the same column differ from each other at $P<0.01$.
} 
compromised chromosomal composition is a factor that reduces NT efficiency, improper epigenetic reprogramming of the donor nucleus probably has a greater impact on NT efficiency. Further research evaluating the molecular machinery involved in nuclear reprogramming before and after activation will pave the way to a better understanding of the mechanisms of nuclear reprogramming and the development of new strategies to improve the efficiency of the process.

\section{Acknowledgements}

The authors would like to thank Swift and Company for generous access to abattoir ovaries and the JR Simplot Company for providing funding and recipients for this project. This paper is published as Utah Agricultural Experiment Station Publication No. 7736. The authors declare that there is no conflict of interest that would prejudice the impartiality of this scientific work.

\section{References}

Akagi S, Yokota M, Neguebi T, Taniyama A, Fuebimoto D \& Izaile Y 2001 The timing of fusion and chemical activation in nuclear transfer affects development potential of bovine embryos. Theriogenology 55252.

Barnes FL, Collas P, Powell R, King WA, Westhusin M \& Shepherd D 1993 Influence of recipient oocyte cell cycle stage on DNA synthesis, nuclear envelope breakdown, chromosome constitution, and development in nuclear transplant bovine embryos. Molecular Reproduction and Development 36 33-41.

Booth PJ, Viuff D, Tan S, Holm P, Greve T \& Callesen H 2003 Numerical chromosome errors in day 7 somatic nuclear transfer bovine blastocysts. Biological Reproduction 68 922-928.

Bourc'his D, Le Bourhis D, Patin D, Niveleau A, Comizzoli P, Renard JP \& Viegas-Pequignot E 2001 Delayed and incomplete reprogramming of chromosome methylation patterns in bovine cloned embryos. Current Biology 11 1542-1546.

Bureau WS, Bordignon V, Leveillee C, Smith LC \& King WA 2003 Assessment of chromosomal abnormalities in bovine nuclear transfer embryos and in their donor cells. Cloning Stem Cells 5 $123-132$.

Burgoyne PS, Holland K \& Stephens R 1991 Incidence of numerical chromosome anomalies in human pregnancy estimation from induced and spontaneous abortion data. Human Reproduction 6 555-565.

Campbell KH, Ritchie WA \& Wilmut I 1993 Nuclear-cytoplasmic interactions during the first cell cycle of nuclear transfer reconstructed bovine embryos: implications for deoxyribonucleic acid replication and development. Biological Reproduction 49 933-942.

Campbell KH, Loi P, Otaegui PJ \& Wilmut I 1996 Cell cycle co-ordination in embryo cloning by nuclear transfer. Review of Reproduction 1 40-46.

Cezar GG, Bartolomei MS, Forsberg EJ, First NL, Bishop MD \& Eilertsen KJ 2003 Genome-wide epigenetic alterations in cloned bovine fetuses. Biological Reproduction 68 1009-1014.

Choi JY, Kim CI, Park CK, Yang BK \& Cheong HT 2004 Effect of activation time on the nuclear remodeling and in vitro development of nuclear transfer embryos derived from bovine somatic cells. Molecular Reproduction and Development 69 289-295.
Chung YG, Ratnam S, Chaillet JR \& Latham KE 2003 Abnormal regulation of DNA methyltransferase expression in cloned mouse embryos. Biological Reproduction 69 146-153.

Czolowska R, Modlinski JA \& Tarkowski AK 1984 Behaviour of thymocyte nuclei in non-activated and activated mouse oocytes. Journal of Cell Science 69 19-34.

Dean W, Santos F, Stojkovic M, Zakhartchenko V, Walter J, Wolf E \& Reik W 2001 Conservation of methylation reprogramming in mammalian development: aberrant reprogramming in cloned embryos. PNAS 98 13734-13738.

Hill JR 2002 Abnormal in utero development of cloned animals: implications for human cloning. Differentiation 69 (4-5) 174-178.

Kang YK, Park JS, Koo DB, Choi YH, Kim SU, Lee KK \& Han YM 2002 Limited demethylation leaves mosaic-type methylation states in cloned bovine pre-implantation embryos. EMBO Journal 21 1092-1100.

Kang YK, Yeo S, Kim SH, Koo DB, Park JS, Wee G, Han JS, Oh KB, Lee KK \& Han YM 2003 Precise recapitulation of methylation change in early cloned embryos. Molecular Reproduction and Development 66 32-37.

Kato Y, Tani T \& Tsunoda Y 2000 Cloning of calves from various somatic cell types of male and female adult, newborn and fetal cows. Journal of Reproduction and Fertility 120 231-237.

Kim YS, Lee SL, Ock SA, Balasubramanian S, Choe SY \& Rho GJ 2005 Development of cloned pig embryos by nuclear transfer following different activation treatments. Molecular Reproduction and Development 70 308-313.

Li GP, Bunch TD, White KL, Aston KI, Meerdo LN, Pate BJ \& Sessions BR 2004a Development, chromosomal composition, and cell allocation of bovine cloned blastocyst derived from chemically assisted enucleation and cultured in conditioned media. Molecular Reproduction and Development 68 189-197.

Li GP, White KL, Aston KI, Meerdo LN \& Bunch TD 2004b Conditioned medium increases the polyploid cell composition of bovine somatic cell nuclear-transferred blastocysts. Reproduction $127221-228$.

Liu L, Shin T, Pryor JH, Kraemer D \& Westhusin M 2001 Regenerated bovine fetal fibroblasts support high blastocyst development following nuclear transfer. Cloning 3 51-58.

Mann MR, Chung YG, Nolen LD, Verona RI, Latham KE \& Bartolomei MS 2003 Disruption of imprinted gene methylation and expression in cloned preimplantation stage mouse embryos. Biological Reproduction $69902-914$.

Nakao M 2001 Epigenetics: interaction of DNA methylation and chromatin. Gene 278 (1-2) 25-31.

Santos F \& Dean W 2004 Epigenetic reprogramming during early development in mammals. Reproduction 127 643-651.

Santos F, Zakhartchenko V, Stojkovic M, Peters A, Jenuwein T, Wolf E, Reik W \& Dean W 2003 Epigenetic marking correlates with developmental potential in cloned bovine preimplantation embryos. Current Biology 13 1116-1121.

Shi W \& Haaf T 2002 Aberrant methylation patterns at the two-cell stage as an indicator of early developmental failure. Molecular Reproduction and Development 63 329-334.

Shi W, Zakhartchenko V \& Wolf E 2003 Epigenetic reprogramming in mammalian nuclear transfer. Differentiation 71 91-113.

Shi W, Dirim F, Wolf E, Zakhartchenko V \& Haaf T 2004 Methylation reprogramming and chromosomal aneuploidy in in vivo fertilized and cloned rabbit preimplantation embryos. Biological Reproduction 71 340-347.

Telford NA, Watson AJ \& Schultz GA 1990 Transition from maternal to embryonic control in early mammalian development: a comparison of several species. Molecular Reproduction and Development 26 90-100.

Wakayama T, Perry AC, Zuccotti M, Johnson KR \& Yanagimachi R 1998 Full-term development of mice from enucleated oocytes injected with cumulus cell nuclei. Nature 394 (6691) 369-374. 
Wells DN, Misica PM, McMillan WH \& Tervit HR 1998 Production of cloned bovine fetuses following nuclear transfer using cells from a fetal fibroblast cell line. Theriogenology 49330.

Wells DN, Misica PM, Forsyth JT, Berg MC, Lange JM, Tervit HR \& Vivanco WH 1999 The use of adult somatic cell nuclear transfer to preserve the last surviving cow of the Enderby island cattle breed. Theriogenology $\mathbf{5 1} 217$.

Wrenzycki C, Wells D, Herrmann D, Miller A, Oliver J, Tervit R \& Niemann H 2001 Nuclear transfer protocol affects messenger RNA expression patterns in cloned bovine blastocysts. Biological Reproduction 65 309-317.
Zhu ZY, Chen DY, Li JS, Lian L, Lei L, Han ZM \& Sun QY 2003 Rotation of meiotic spindle is controlled by microfilaments in mouse oocytes. Biological Reproduction 68 943-946.

Received 1 March 2005

First decision 16 August 2005

Revised manuscript received 2 September 2005

Accepted 6 September 2005 